\title{
Evaluation of Seismic Pounding between Adjacent Buildings
}

\author{
Nasser Zaki Ahmed
}

Mohamed Raafat
Mohamed Abdel-Mooty

\begin{abstract}
Insufficient separation distance between adjacent buildings may lead to their pounding resulting in damage or failure during strong earthquakes. Accordingly, most of the design codes specify a minimum separation or gap distance between adjacent buildings to prevent this pounding phenomenon. This research studies the seismic pounding between adjacent reinforced concrete buildings under various ground motions. It also investigates the factors affecting pounding and proposes a technique to mitigate it. Buildings are modeled as two-dimensional frames to idealize the adjacent buildings. The total of 10 different cases of adjacent frames with different height combinations. Nonlinear time history analysis is utilized using finite element computer program ETABS. Real earthquake records are scaled and used to simulate ground motion. Gap element is used to model pounding between buildings. The effect of variation of some design parameters on seismic pounding is investigated. Different parameters are studied including the separation distance, dynamic characteristic of the buildings and the number of the floor of the adjacent buildings. A technique for mitigation of pounding effect based on rigidly connecting selected floors in adjacent buildings is proposed and numerically tested. The results of the study are analyzed and the effect of the different factors are evaluated.
\end{abstract}

Keywords - structural pounding, dynamic analysis, poudning mitigation.

\section{Introduction}

Structures with large plan dimensions, as well as those with parts ofa different number of floors, might require to separate them into two or more parts by expansion joints or separation distances. If the separation distance, during an earthquake, is not sufficient to accommodate the relative lateral deformations of the adjacent buildings, they might come into contacts or collide with each other. This collision between adjacent buildings is referred to as seismic pounding. This pounding may cause local damage, significant damage or even total collapse of the adjacent buildings depending on the earthquake strength.

Recently, there has been a great deal of interest in studying this phenomenon to prevent damage that may occur during seismic excitation.

Nasser Zaki Ahmed/ Assistant Professor

Faculty of Engineering / Beni-Suef University

Egypt

Mohamed Raafat/ Graduate Student

Faculty of Engineering / Cairo University

Egypt

Mohamed Ahmed Naiem / Professor

Faculty of Engineering / Cairo University

Egypt
The pounding phenomenon has been studied by researchers due to its impact on the seismic design and analysis of adjacent structures. Different modeling techniques have been used to idealize adjacent buildings. Also, pounding effect has been simulated using various approaches to evaluate pounding force. Factors which affect pounding have been addressed and its effect on pounding has been investigated. Anagnostopoulos 1988 [1] investigated pounding of serval adjacent buildings in a block using a simplified model of the single-degree-of-freedom system and pounding was simulated by impact elements. It was revealed that end building displaced more than the interior one. Maison, et al 1992 [2] formulated a solution of multiple-degree-of-freedom system for a 15-story building adjacent to 8-story building. M. Abdel-Mooty, et al. 2009 [3] used two-dimensional frame structures to model the buildings and gap element to simulate the pounding effect. Detailed parametric study was carried out to study the effect of various parameters on the pounding. P. D. Pawarel, et al. 2014 [4] studied the impact between L-shape buildings. Pounding was represented by gap element as linear spring. Soil effect was investigated to show its effect on pounding forces. Chaitanya 2015 [5] studied seismic pounding effect between adjacent buildings using linear and nonlinear dynamic analysis. Buildings were modeled using 3D finite element model using ETABS computer program. Naderpour 2016 [6] studied the case of pounding between two adjacent buildings by the application of single degree-of-freedom structural models Impact was numerically simulated with the use of a nonlinear viscoelastic mode.

. The main objectives of this research are:

- Enhance modeling of pounding and estimation of the pounding force between adjacent structures

- Identify the effect of the parameters that influence pounding such as gap distance, seismic record and height of the buildings

- Study the effect of coupling of the adjacent building at different floor as a mean of mitigating the pounding_force and effect.

\section{Code Requirements to Avoid Pounding}

Most of the design codes and standards allow a minimum separation distance or gap between adjacent buildings to avoid or to prevent pounding. The specified separation or gap is mainly depending on the maximum displacement of the adjacent buildings. The methods used to calculate this gap are different from code to code because of the needs to calculate reliable and economic separation. This part of the paper summarizes the provision used in different codes: to calculate the safe separation. 
The sum of the maximum displacement for each building is used by the Canadian code while a quadratic combination of the maximum displacements is used by the French code. International building code, IBC2009 [7] as well as the ASCE7-10 [8] use the following equation in calculation of the separation distance

$$
\delta_{M}=\frac{C_{d} \delta_{\max }}{I}
$$

where, $\delta_{\max }$ is the maximum elastic displacement that occurs anywhere in a floor by the application of the design base shear to the structure. $C_{d}$ is the deflection amplification factor and ' $I$ ' is the importance factor for seismic loading.

The uniform building code UBC97 [9], the Egyptian code of practice [10] and the Eurocode 8 [11] employ the following equation:

$\delta_{M}=\sqrt{\left(\delta_{M 1}\right)^{2}+\left(\delta_{M 2}\right)^{2}}$

Where $\delta_{M 1}$ and $\delta_{M 2}$ are the peak displacement response of adjacent structures

\section{Numerical Models and Analysis Procedure}

Researchers attempted various types of analysis models to simulate pounding. Among these models are single degree of freedom and; multi-degree of freedom that can be; two-dimensional model or three-dimensional models. In this study, two-dimensional models were utilized. This type of modeling is accepted in symmetric structures where torsion modes are not considered. Two reinforced concrete buildings were selected to model the pounding effect. The two buildings are modeled as a two-dimensional frame where columns and beams are idealized by frame elements. The selected buildings are assumed to have the same floor level. Also, floors are connected by a rigid diaphragm. Pounding was simulated using gap element. The buildings are analyzed using ETABS finite element program where both of eigenvalue analysis and time history analysis are carried out to obtain natural frequency and pounding force resepctivly. Then, earthquakes of low, moderate and high ground motion are applied. Buildings description including geometry and material properties, gap element stiffness, and ground motion excitation are summarized below.

\section{A. Building Model:}

The selected buildings are comprised of two-dimensional four bays and eight bays frame, each bay is of five-meter length. The floor height is three-meter for the two buildings. The buildings layout and elevations are shown in Fig. 1. The two buildings are designed according to Egyptian code provision for design and construction of reinforced concrete design ECP 2012 edition [11] and dimensions of different structural elemets are shown in Table_1.. They are designed to satisfy both gravity and lateral loads requirements. The stiffness of the different structural elements is reduced to account for concrete cracking and expected damage. A 3D finite element model is constructed for each of the selected buildings. An integrated building design software ETABS is utilized in modeling and analysis. Columns are assumed fixed at the foundation. Different building materials used in analysis and the design of the buildings are:

- Concrete cube compressive strength is $25 \mathrm{~N} / \mathrm{mm}^{2}$, modulus of elasticity is $21000 \mathrm{~N} / \mathrm{mm}^{2}$ and Poisson's ratio is 0.2

- Reinforcing steel bars yield strength is $360 \mathrm{~N} / \mathrm{mm}^{2}$, modulus of elasticity is $210000 \mathrm{~N} / \mathrm{mm}^{2}$, and Poisson's ratio is 0.3

Building heights presented in this paper are:

- 3 story building adjacent to 6-story building

- $\quad 8$-story building adjacent to 12 -story building

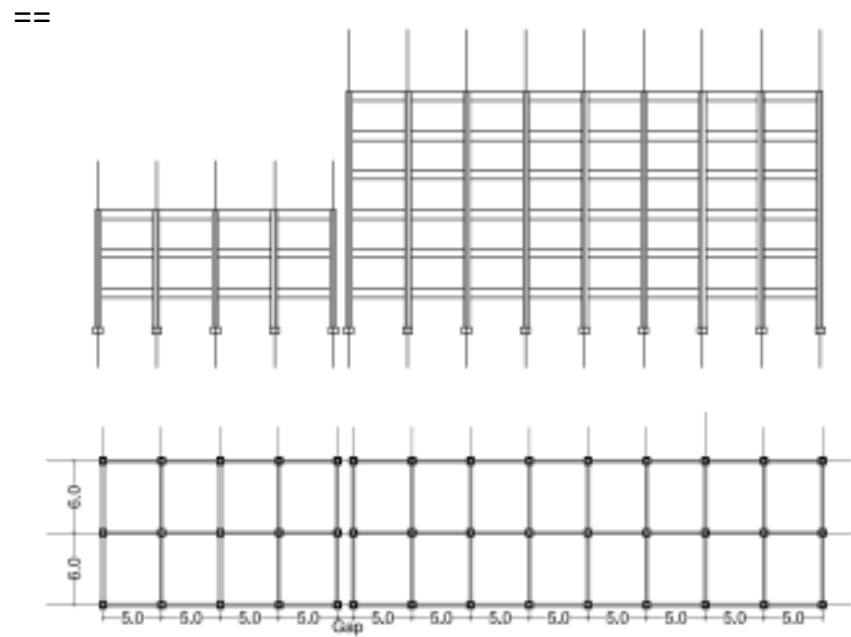

Figure 1. Layout and Elevation of the studied buildings.

TABLE I. DIMENSIONS OF THE STUDIED STRUCTURES

\begin{tabular}{|l|l|l|l|}
\hline Building & \multicolumn{1}{|c|}{$\begin{array}{c}\text { Exterior } \\
\text { Column } \\
(\mathbf{m m})\end{array}$} & $\begin{array}{c}\text { Interior } \\
\text { column }(\mathbf{m m})\end{array}$ & $\begin{array}{c}\text { Beam } \\
(\mathbf{m m})\end{array}$ \\
\hline 3 story & $250 \times 250$ & $400 \times 400$ & $300 \times 700$ \\
\hline 6 story & $350 \times 350$ & $500 \times 500$ & $300 \times 700$ \\
\hline 8 story & $400 \times 400$ & $600 \times 600$ & $300 \times 700$ \\
\hline 12 story & $550 \times 550$ & $700 \times 700$ & $300 \times 700$ \\
\hline
\end{tabular}

\section{B. Gap Element:}

Gap (compression-only) element is used to model the pounding force between buildings. Non-linear properties of the gap element are taken into consideration by the used software program. The gap element transmits axial compression force only. Both of the stiffness of the gap and the separation distance between buildings are required to model that gap element. The relationship between the force generated ien the link and the deformation is given as [12]:

$$
\begin{aligned}
& F_{L}=K_{s}\left(d-d_{s}\right) \quad \text { If }\left(d-d_{s}\right)<0 \\
& F_{L}=0 \quad \text { otherwise }
\end{aligned}
$$

where $F_{L}$ is the pounding force, $K_{s}$ is the gap stiffness, $d$ is the building displacement, and $d_{s}$ is the separation distance. 
Proc. of Fifth International Conference On Advances in Civil, Structural and Mechanical Engineering -ACSM 2016 Copyright (c) Institute of Research Engineers and Doctors, USA .All rights reserved.

ISBN: 978-1-63248-105-4 doi: 10.15224/ 978-1-63248-105-4-24

The used separation distance in this study is:

- $5 \mathrm{~mm}$ separation

- $10 \mathrm{~mm}$ separation

- $20 \mathrm{~mm}$ separation

Also, the stiffness of the gap elements is taken as approximately 20 times the stiffness of the stiffer building

\section{Seismic Action}

To study the effect of seismic ground motion on pounding force, an earthquake with low, moderate and high ground motion were selected which are:

- Friuli earthquake

- Newhall earthquake

- Sylmar earthquake

Table 3 shows the characteristics properties of the selected earthquakes. Also, Figure 2-4 shows the acceleration time history for the selected earthquake records.

TABLE II. CHARACTERISTIC OF THE SELECTED GROUND MOTION

\begin{tabular}{|l|c|}
\hline Earthquake & $\begin{array}{c}\text { Peak. ground } \\
\text { acceleration }(\mathbf{g})\end{array}$ \\
\hline Friuli & 0.31 \\
\hline Newhall & 0.60 \\
\hline Sylmar & 0.76 \\
\hline
\end{tabular}

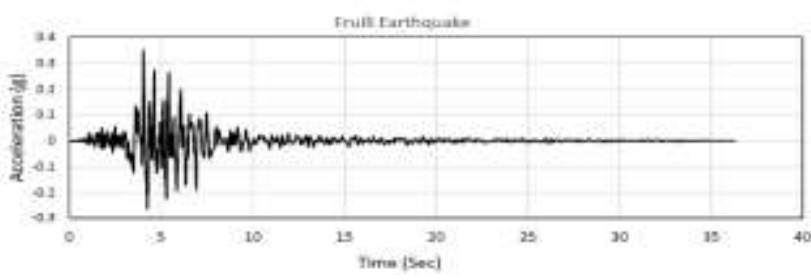

Figure 2. Acceleration time history of Friuli earthquake.

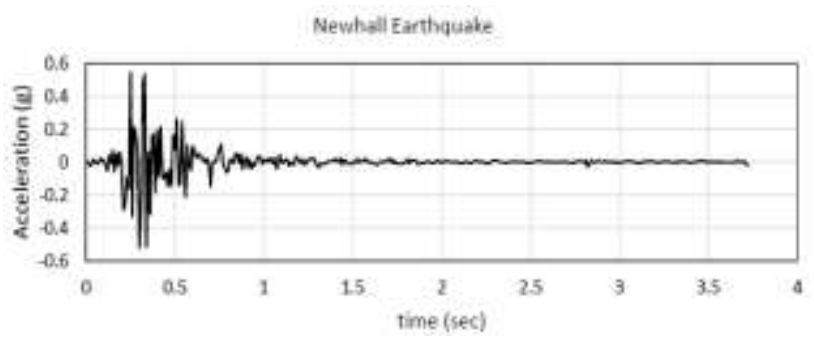

Figure 3. Acceleration time history of Newhall earthquake

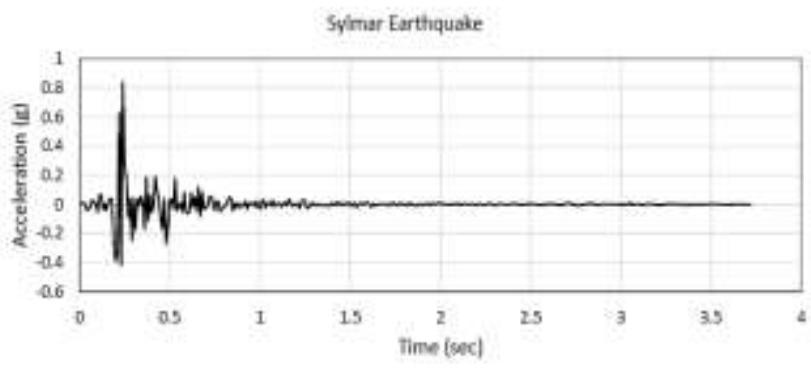

Figure 4. Acceleration time history of Sylmar earthquake

\section{Results and Parametric Study}

The distribution of pounding forces along the building height for 3-story building to 6-story building is shown in Figure 5 to 7 with different gap distances. Also, the effect of gap distance and seismic record is shown in Figure 8.

It could be seen that the pounding force is considerably affected by the separation distance. The maximum pounding force is decreased by $20 \%$ for increasing the gap distance from $5 \mathrm{~mm}$ to $10 \mathrm{~mm}$ while this decrease reaches $80 \%$ for separation distance of $20 \mathrm{~mm}$.

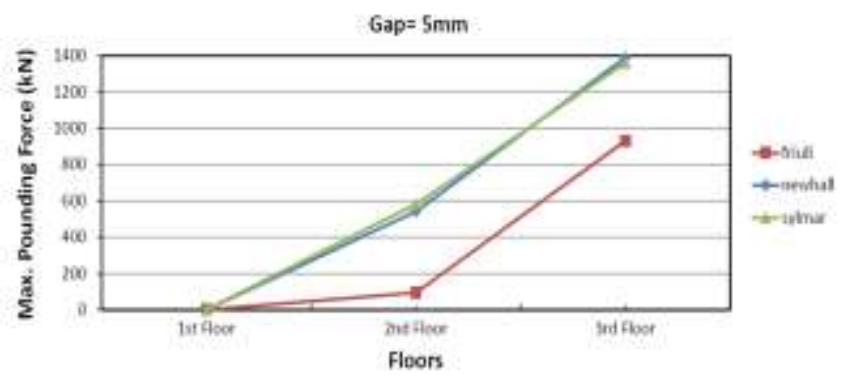

Figure 5. Maximum pounding force $(\mathrm{kN})$ along the building height for 3-story building adjacent to 6 -story building $-\mathrm{Gap}=5 \mathrm{~mm}$

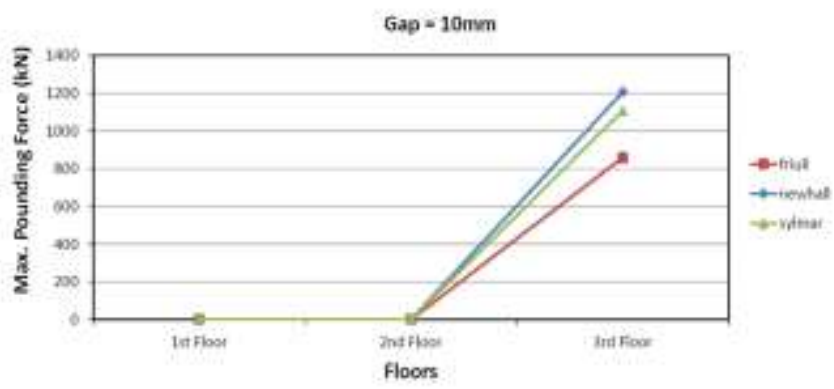

Figure 6. Maximum pounding force $(\mathrm{kN})$ along the building height for 3 -story building adjacent to 6 -story building- $\mathrm{Gap}=10 \mathrm{~mm}$

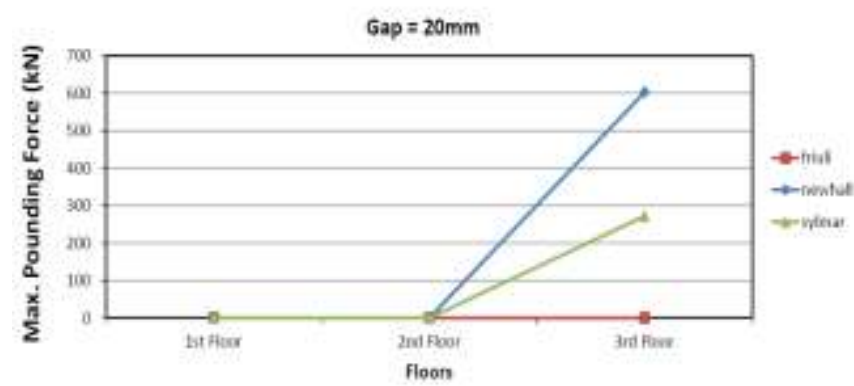

Figure 7. Maximum pounding force $(\mathrm{kN})$ along the building height for 3 -story building adjacent to 6 -story building $-\mathrm{Gap}=20 \mathrm{~mm}$ 
Proc. of Fifth International Conference On Advances in Civil, Structural and Mechanical Engineering -ACSM 2016 Copyright (c) Institute of Research Engineers and Doctors, USA .All rights reserved.

ISBN: 978-1-63248-105-4 doi: 10.15224/ 978-1-63248-105-4-24

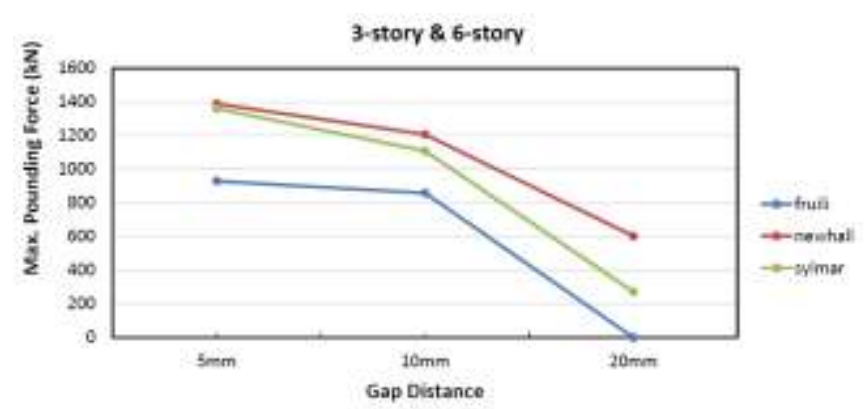

Figure 8. Effect of gap distance and seismic record on pounding force for 3 -story building adajcent to 6 -story building

Also, the distribution of pounding forces along the building height for 8 -story to 12 -story building is shown in Figures 9 to 11 with different gap distances. The effect of gap distance and seismic record is shown in Figure 12. The same trend for the pounding force has been observed.

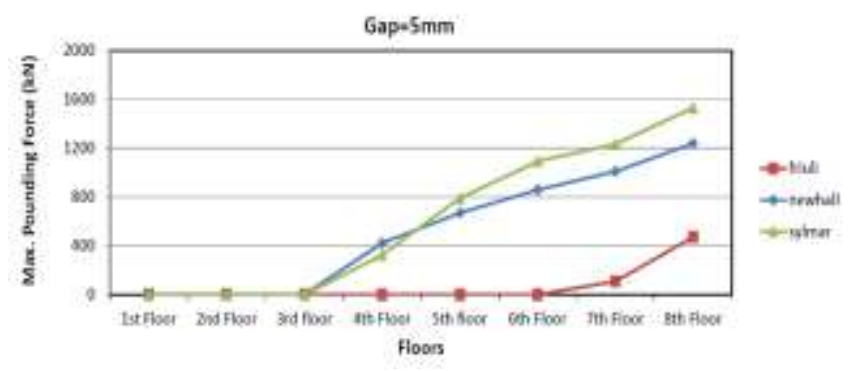

Figure 9. Maximum pounding force $(\mathrm{kN})$ along the building height for 8 -story adjacent to 12 -story building $-\mathrm{Gap}=5 \mathrm{~mm}$

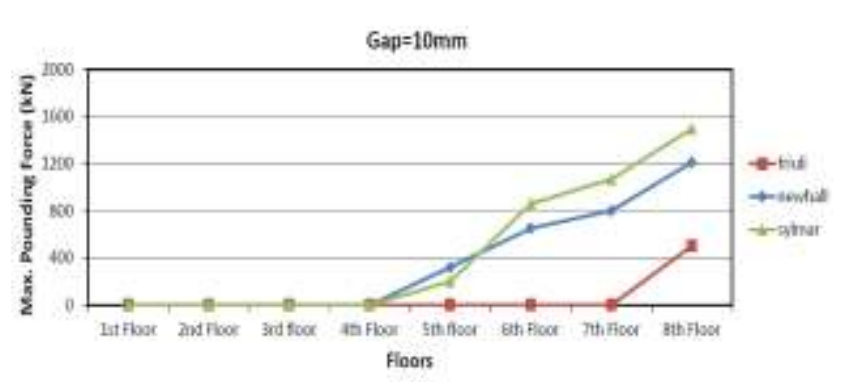

Figure 10. Maximum pounding force $(\mathrm{kN})$ along the building height for 8 -story building adjacent to 12 -story building $-\mathrm{Gap}=10 \mathrm{~mm}$

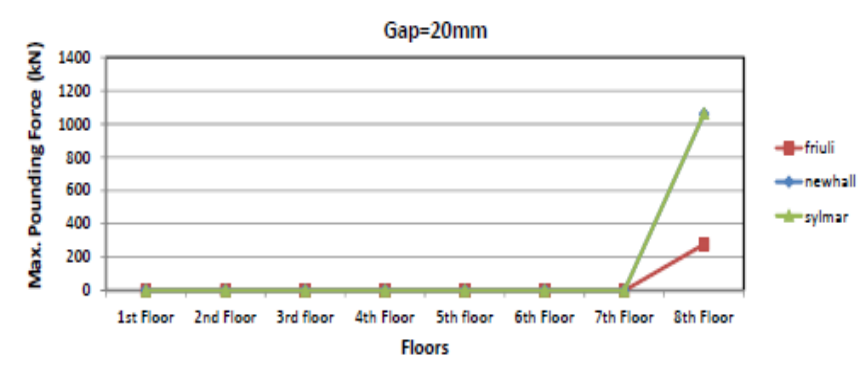

Figure 11. Maximum pounding force $(\mathrm{kN})$ along the building height for 8 -story building adjacent to 12 -story building - Gap $=20 \mathrm{~mm}$

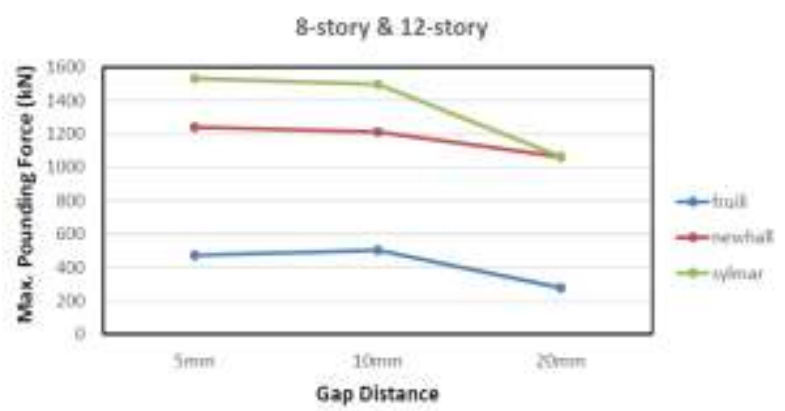

Figure 12. Effect of gap distance and seismic record on pounding force for 8 -story building adjacent to 12 -strory building

\section{Pounding Mitigation}

Most of the previous research focus on reducing the pounding effect through increasing the separation distance between buildings, increase the stiffness of the lateral load resisting system of the buildings, and use of viscous dampers to absorb the deformation between buildings. In this study, rigidly connecting selected floors in the adjacent buildings is proposed to mitigate pounding. Connections at different floor level are investigated to study the critical locations which reduce pounding with a minimum effect on the structural safety of the connected structures

Rigid connection was attempted at different floor levels. Higher levels were selected for this connection to minimize the effect of temperature on columns

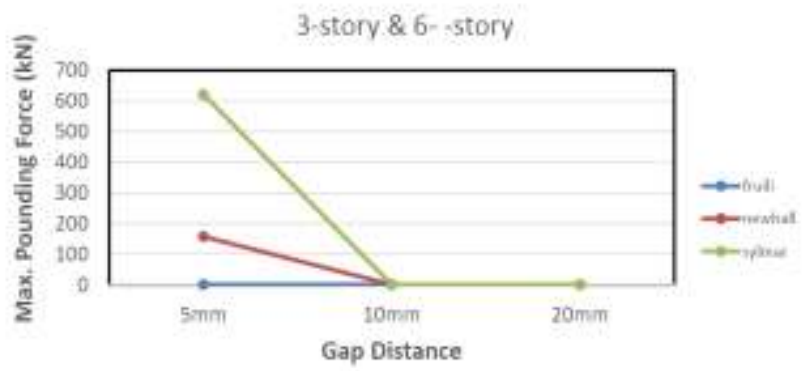

Figure 13. Maximum pounding force on building for 3-strory building adjacent to 6 -story building ( $2^{\text {nd }}$ floor connection).

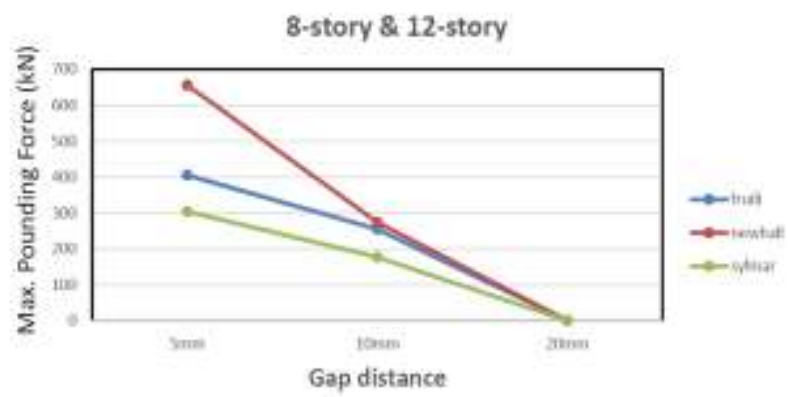

Figure 14. Maximum pounding force on building for 8-story building adjacent to 8-story building ( $2^{\text {nd }}$ floor connection) 
A comparison between maximum pounding force on buildings without connection and with connection at mid height for different gap distance under the effect of Newhall earthquake are shown on Figures 15 to 16.

It could be observed that there is a significant decrease in the pounding force values between buildings with connections compared to those without connections.

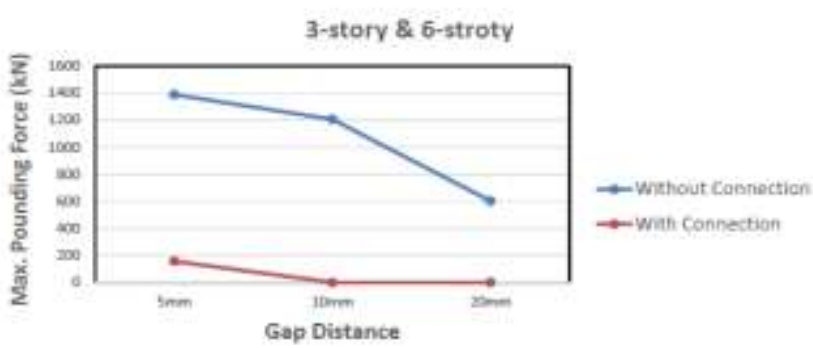

Figure 15. Comparison of maximum pounding force on building for building without connection and with connection at $2^{\text {nd }}$ floor (Newhall earhquake)

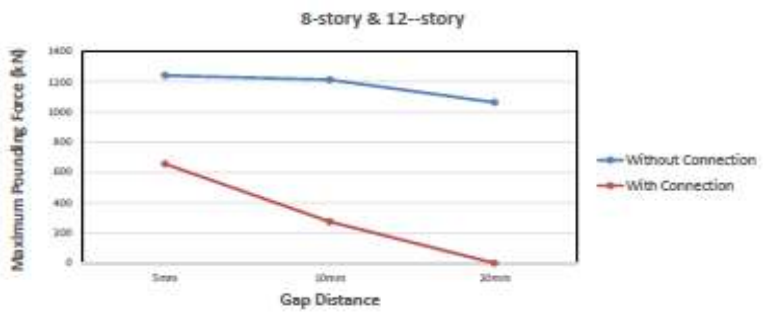

Figure 16. Comparison of maximum pounding force on building for building without connection and with connection at $4^{\text {nd }}$ floor (Newhall earhquake

\section{CONCLUSIONS}

- Pounding force is significantly affected by the seismic record and earthquake characteristics.

- Height of the buildings has a considerable effect on the pounding effect where 8-story to 12-story building has a higher pounding force than that of 3 story to 6-story building

- Gap distance play an important role on pounding force in the pounding force effect between buildings. Increasing the gap distance considerably deceases the pounding force

- Rigid connection between selected floors in adjacent buildings, particularly at top floor, is an efficient tool to mitigate the pounding effect. However, connected building should be carefully checked for its new dynamic characteristic. Also, in some cases temperature check on the connected buildings need to be verified.

\section{References}

[1] Anagnostopoulos SA "Pounding of buildings in seris during during earthquake," Earthquake Engineering \& Structural Dynamics, 16(3):443-456, 1988

[2] Maison BF, Kasai K "Dynamics of pounding when two buildings collide," Earthquake Engineering \& Structural Dynamics, 21(9):771786, 1992

[3] M. Abdel-Mooty, et al "Modeling and analysis of factors affecting seismic pounding of adjacent buildings," Earthquake Resistance Engineering Structures VII: 127-138, 2009.

[4] P. D. Pawar, P. B. Murnal "Effect of seismic pounding on adacent blocks of unsymmetrical buildings consderr soil structure interaction," International jornal of Emerging Technology and advanced Engineering, 1992

[5] J. D. Chaitany Kumar, et al "Seismic pounding of the adjacent buildings with different heights," International Jornal of Engineering Research and Sience \& Technology , 4(4, 2015.

[6] H. Naderpour, R. C. Barros, S. M. Khatami, and R. Jankowski "Numerical study on pounding between two adjacent buildings under earthquake excitation," Shock and Vibration, 2016.

[7] International building code, IBC 2012, International code council, USA.

[8] American society of Civil Engineering for Minumum Design Loads for Buildings and Other Structures, ASCE/SEI 7-10, USA

[9] Uniform building code, UBC1997, International conference on building officials, Whittier, California, USA

[10] Egyptian code of practice for computing loads and forces on structures, ECP 2012.

[11] Design of structures for earthquake resistance part 1: General rules, seismic actions and rules for building, Eurocode 8 .

[12] CSI Analysis refrence manual, Computers and Structures, Inc

About Authors:

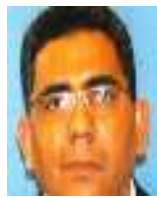

Dr. Nasser Zaki Ahmed

Assistant Professor, Civil Engineering Department, Faculty of Engineering, Beni-Suef University.

Prof. Dr. Mohamed Abdel-Mooty

Professor, Structural Engineering Department, Faculty of Engineering, Cairo University. 